\title{
On the developmental theory of ageing. II. The effect of developmental temperature on longevity in relation to adult body size in D. melanogaster
}

\author{
B. J. ZWAAN, R. BIJLSMA \& R. F. HOEKSTRA* \\ Department of Genetics, University of Groningen, Kerklaan 30, 9751 NN Haren and "Department of Genetics, \\ Agricultural University, Dreyenlaan 2, 6703 HA Wageningen, The Netherlands
}

\begin{abstract}
Flies from a wild type strain of Drosophila melanogaster, previously kept at $25^{\circ} \mathrm{C}$, were reared at either 20,25 or $29^{\circ} \mathrm{C}$. As expected, developmental time and adult body size decreased with increasing temperature. Adult longevity of flies reared at $25^{\circ} \mathrm{C}$ was slightly greater than that of flies raised at 20 or $29^{\circ} \mathrm{C}$ when measured at all three temperatures. This may reflect the laboratory history of the strain. On the whole, it appeared that longevity was independent of adult body size. These results support our previous conclusion (Zwaan et al., 1991) that developmental time and body size are not causally related to longevity in 'environmental' studies. It is stressed, that genetic analysis is needed to investigate the reputed correlation between development and ageing.
\end{abstract}

Keywords: ageing, developmental time, Drosophila melanogaster, temperature.

\section{Introduction}

The developmental theory of ageing is the major nonevolutionary theory of ageing (Lints, 1978; 1988). According to this theory, ageing is a built-in consequence of differentiation and development. This may imply that development and ageing are directed by the same set of genes, i.e. that these processes are related genetically (Zwaan et al., 1991). In that case environmentally induced alteration of development could be reflected in the time of onset of ageing and/or variation in life-span. Indeed, experiments with homeotherms and insects suggest a genetic relationship between development and longevity (Lints, 1978; Mayer \& Baker, 1985). Indeed, Comfort (1968) has argued that 'the only likely way of prolonging vigour will prove to be through stretching the development programme as a whole'. The developmental period of Drosophila can be prolonged through manipulation of temperature (Powsner, 1935) and larval density (Barker \& Podger, 1970).

With respect to temperature, Alpatov \& Pearl (1929) demonstrated that flies reared at $18^{\circ} \mathrm{C}$ outlived flies reared at $28^{\circ} \mathrm{C}$ at three temperatures during the adult stage. Burcombe \& Hollingsworth (1970) and Lints \& Lints (1971a) obtained similar results. Further work found a positive correlation between develop- mental time and lifespan (Lints \& Lints, 1971b) and these authors interpreted their results as evidence for the developmental theory of ageing. Cohet (1975) obtained results showing an optimal developmental temperature for longevity but in the temperature range that is usually studied for Drosophila melanogaster $\left(17-30^{\circ} \mathrm{C}\right)$, a negative correlation was found between adult longevity and developmental temperature. On the other hand, Economos \& Lints (1986) concluded that within the $16-29^{\circ} \mathrm{C}$ temperature range, the adult lifespan was independent of developmental temperature.

Temperature during development also influences adult body size. In general, a negative correlation exists between developmental temperature and body size (Lints \& Lints, 1971b). Several authors have suggested that the increased longevity of flies reared at lower temperatures could be due to their larger body size (Alpatov \& Pearl, 1929; Burcombe \& Hollingsworth, 1970; Mayer \& Baker, 1985). Indeed, in Drosophila there is evidence, for a given developmental temperature, that larger flies live longer (Tantawy \& Vetukhiv, 1960; Kidwell \& Malick, 1965; Partridge \& Farquhar, 1981; Partridge et al., 1986). This might imply that developmental time is not causally related to longevity.

The purpose of this study is twofold. (i) To study the effect of developmental temperature on adult longevity and to examine the consistency of this effect for several 
temperatures during the adult stage. (ii) To determine the correlation between adult body size and longevity both within and between groups of flies reared at different temperatures.

\section{Materials and methods}

\section{Strain and culture conditions}

The Groningen 83 wild type strain was used. It is considered to possess a large amount of genetic variation (Zwaan et al., 1991). The experiments were carried out between February and September 1989. All flies were raised in vials with $8 \mathrm{ml}$ of standard medium (Zwaan et al., 1991). We used three temperatures to rear the flies, 20,25 and $29^{\circ} \mathrm{C}$ (developmental temperature). This rearing procedure was followed in two independent experiments. The first experiment aimed to establish the effect of developmental temperature on adult body size and longevity. The second experiment aimed to determine the effect of developmental temperature on viability (egg-to-adult survival) and developmental time. To obtain eggs, 40 groups of about 30 pairs of flies were allowed to lay eggs on standard medium. In the first experiment a 3-h and in the second experiment a 12-h laying period was used. The egg-density was 100 per vial. Each temperature group consisted of 40 vials in the first and of 15 vials in the second experiment. Samples of flies for the longevity assays were taken during peak eclosion. All flies were collected as virgins and the sexes were kept separately. Samples of flies from each developmental temperature, were set up at 20,25 and $29^{\circ} \mathrm{C}$ (adult temperature). Therefore, nine experimental groups, were constructed for longevity measurements. Flies were also sampled for adult body size measurements. A detailed description of the methods and calculations of developmental time and viability measurements is given in Zwaan et al. (1991).

\section{Adult body size}

Twenty female and male flies were randomly sampled from each developmental temperature group. Adult body weight and wing size were measured for each individual fly. Adult body weight was measured at an age of 6 days, to the nearest $0.001 \mathrm{mg}$. The length of the third longitudinal vein (anterior crossvein to wingtip) was taken as a measure of body size (Prout, 1958). Generally, the right wing of the fly was pulled out and immersed in a drop of euparal, on a microscopic slide. Measurements were carried out using an ordinary microscope $(5 x)$ with an ocular micrometer (Prout, 1958).

\section{Longevity in relation to body size}

All flies were housed singly and as virgins because we believe that these conditions give an accurate determination of adult longevity (Zwaan et al., 1991). All nine experimental groups consisted of 50 female and 50 male flies, and this sample size could be maintained because escaped flies and accidental deaths were replaced by reserve flies throughout the experiment. The vials were assayed three times a week for deceased individuals and the longevity (in days) of these flies was taken as the midpoint between two successive scorings. This procedure allowed us to calculate mean longevity for each group. Vials, containing $5 \mathrm{ml}$ of standard medium, were replaced once a week. Wings of deceased individuals were immersed in euparal, as described above, to obtain a measure of adult body size. In this way for both sexes and each temperature group the correlation could be calculated between longevity and body size. During the experiment wings of some flies were damaged to such an extent that measurement of winglength became impossible. This was particularly a problem for females at the adult temperature of $20^{\circ} \mathrm{C}$, because of the relative long life of these flies. Therefore, sample sizes of winglength were not uniform for each temperature group (Table 5).

\section{Survival curves}

We used the method devised by Ricklefs (1967) to fit logistic and Gompertz equations to survival curves; this was originally developed for growth curves. Survival percentages were replaced by the corresponding conversion factors and plotted as a function of time. Linear regression was applied to these data and the resulting regression line transformed to the general survival equation. Correlation coefficients of the regression lines were always statistically significant and greater than 0.94 (mean: logistic $0.984 \pm 0.009$ and Gompertz $0.985 \pm 0.012$ ). Only survival percentages between 10 and 90 per cent were used, because this interval is generally taken as the senescent period (Arking, 1987). Using these survival equations we were able to calculate the pre-senescent $\left(L T_{10}\right)$ and the senescent period $\left(L T_{10}\right.$ to $\left.L T_{90}\right)$.

\section{Data analysis}

Analysis of variance was used to ascertain effects of developmental and adult temperature and sex on the above mentioned parameters. Differences between temperature groups were tested for significance using the Student-Newman-Keuls procedure (SNK-test, corrected for unequal sample sizes; Sokal \& Rohlf, 1969). 


\section{Results}

Mean viability and developmental time are shown in Table 1. Lower developmental temperature resulted in a significant increase in developmental time. Temperature during development did not significantly affect viability. Adult body size was significantly decreased with increasing developmental temperature. Both for females $(r=0.67, \quad P<0.001)$ and males $(r=0.89$, $P<0.001)$ a significant positive correlation was found between adult body weight and winglength (Table 2). The somewhat weaker correlation for females was probably caused by the larger variability of female body weight, because of egg production. Therefore, wing size is probably a better measure of adult body size than body weight.

Table 3 describes mean longevity for all nine temperature groups. Survival curves for females and males are given in Fig. 1a and b. Only logistic curves were used, because no evidence could be found for superiority of Gompertz relative to logistic correlation coefficients (After Fisher $z$-transformation, females $t_{16}=0.053$, ns; males $\left.t_{16}=1.301, \mathrm{~ns}\right)$. Table 4 presents the $L T_{10}, L T_{50}$ and $L T_{90}$ values for each temperature group. By comparing Table 3 with Table 4, note that the $L T_{50}$ values correlate well with mean longevity (slope $=1.008, r=0.9997$ ). This, in addition to Kolmogornov-Smirnov tests for normality, indicates that longevity data in our study are normally distributed, and thus, legitimizes the use of analysis of variance and other linear statistics. The analysis of variance of the longevity data showed some significant effects (Table 3). First, there is a highly significant effect of adult temperature on longevity: lifespan is negatively correlated with temperature. Second, adult longevity is significantly affected by temperature during development. After analysis of Table 3 it appears that flies raised at $25^{\circ} \mathrm{C}$ live longer than flies raised at 20 or $29^{\circ} \mathrm{C}$, in five out of six cases. Analysis of differences between groups at one adult temperature revealed only significant differences in two cases. At adult temperature $25^{\circ} \mathrm{C}$, females raised at $20^{\circ} \mathrm{C}$ lived for a significantly shorter period than females raised at 25 or $29^{\circ} \mathrm{C}\left(F_{2,147}=6.88, P<0.01\right.$, SNK-test $)$. At adult temperature $20^{\circ} \mathrm{C}$, males raised at $20^{\circ} \mathrm{C}$ lived for a significantly shorter period than males raised at 25 or

Table 2 Means and standard deviations (in parentheses) of adult body weight $(\mathrm{mg}$ ) and winglength (arbitrary units). Sample sizes were 20 flies.

\begin{tabular}{|c|c|c|c|c|}
\hline & \multicolumn{3}{|c|}{$\begin{array}{l}\text { Developmental temperature } \\
\left({ }^{\circ} \mathrm{C}\right)\end{array}$} & \\
\hline & 20 & 25 & 29 & \\
\hline \multicolumn{5}{|l|}{ Weight } \\
\hline Females & $\begin{array}{c}1.261 \\
(0.11)\end{array}$ & $\begin{array}{r}1.217 \\
(0.07)\end{array}$ & $\begin{array}{c}1.068 \\
(0.15)\end{array}$ & $\begin{array}{l}F_{2.57}=15.4^{*} \\
20=25>29\end{array}$ \\
\hline Males & $\begin{array}{c}0.913 \\
(0.06)\end{array}$ & $\begin{array}{c}0.766 \\
(0.05)\end{array}$ & $\begin{array}{c}0.674 \\
(0.07)\end{array}$ & $\begin{array}{l}F_{2,57}=85.0^{*} \\
20>25>29\end{array}$ \\
\hline \multicolumn{5}{|l|}{ Winglength } \\
\hline Females & $\begin{array}{l}69.1 \\
(2.4)\end{array}$ & $\begin{array}{l}64.1 \\
(1.4)\end{array}$ & $\begin{array}{l}60.3 \\
(2.2)\end{array}$ & $\begin{array}{l}F_{2,57}=90.7^{*} \\
20>25>29\end{array}$ \\
\hline Males & $\begin{array}{l}62.9 \\
(1.6)\end{array}$ & $\begin{array}{l}57.2 \\
(1.5)\end{array}$ & $\begin{array}{l}51.9 \\
(1.8)\end{array}$ & $\begin{array}{l}F_{2.57}=225.3^{*} \\
20>25>29\end{array}$ \\
\hline
\end{tabular}

$* P<0.001$.

Table 1 Means and standard deviations (in parentheses) of viability and developmental time $(h)$

\begin{tabular}{lcccc}
\hline & \multicolumn{4}{c}{ Developmental temperature $\left({ }^{\circ} \mathrm{C}\right)$} \\
\cline { 2 - 4 } & 20 & 25 & 29 & \\
\hline Viability & 0.78 & 0.79 & 0.76 & $F_{2,42}=0.83$ \\
$n$ & $(0.06)$ & $(0.05)$ & $(0.05)$ & \\
& 15 & 15 & 15 & \\
Developmental time & & & & \\
Females & 395.3 & 249.9 & 192.1 & $F_{2,42}=5645.7^{*}$ \\
& $(7.9)$ & $(3.1)$ & $(3.9)$ & $20>25>29$ \\
Males & 402.3 & 251.3 & 196.7 & $F_{2,42}=13421.2^{*}$ \\
& $(4.8)$ & $(2.9)$ & $(2.5)$ & $20>25>29$ \\
\hline
\end{tabular}

$* \mathrm{P}<0.001$. 
Table 3 Means and standard deviations (in parentheses) of adult longevity (days; $n=50$ ), together with an analysis of variance of these data

\begin{tabular}{|c|c|c|c|c|c|c|}
\hline & \multicolumn{6}{|c|}{ Adult temperature $\left({ }^{\circ} \mathrm{C}\right)$} \\
\hline & \multicolumn{2}{|l|}{20} & \multicolumn{2}{|l|}{25} & \multicolumn{2}{|l|}{29} \\
\hline & Female & Male & Female & Male & Female & Male \\
\hline \multicolumn{7}{|l|}{$\begin{array}{l}\text { Developmental } \\
\text { temperature }\left({ }^{\circ} \mathrm{C}\right)\end{array}$} \\
\hline 20 & $\begin{array}{c}79.1 \\
(23.6)\end{array}$ & $\begin{array}{c}78.5 \\
(26.5)\end{array}$ & $\begin{array}{c}49.1 \\
(13.5)\end{array}$ & $\begin{array}{c}57.4 \\
(21.0)\end{array}$ & $\begin{array}{c}30.9 \\
(8.6)\end{array}$ & $\begin{array}{c}30.4 \\
(11.9)\end{array}$ \\
\hline 25 & $\begin{array}{c}87.0 \\
(22.6)\end{array}$ & $\begin{array}{c}92.8 \\
(25.9)\end{array}$ & $\begin{array}{c}59.7 \\
(16.3)\end{array}$ & $\begin{array}{c}63.7 \\
(13.7)\end{array}$ & $\begin{array}{c}33.2 \\
(6.7)\end{array}$ & $\begin{array}{c}31.0 \\
(10.7)\end{array}$ \\
\hline 29 & $\begin{array}{c}81.5 \\
(29.4)\end{array}$ & $\begin{array}{c}89.3 \\
(21.9)\end{array}$ & $\begin{array}{c}57.2 \\
(14.9)\end{array}$ & $\begin{array}{c}56.9 \\
(16.8)\end{array}$ & $\begin{array}{c}34.3 \\
(6.3)\end{array}$ & $\begin{array}{c}26.6 \\
(11.0)\end{array}$ \\
\hline Source & & SS & & d.f. & MS & $F$ \\
\hline \multicolumn{7}{|l|}{ Main effects } \\
\hline Developmental tem & perature $(a)$ & & 52.3 & 2 & 3676.1 & $11.2^{* *}$ \\
\hline Adult temperature & & $431^{\prime}$ & 31.4 & 2 & 215865.7 & $657.9^{* *}$ \\
\hline $\operatorname{Sex}(c)$ & & & 00.2 & 1 & 600.2 & 1.8 \\
\hline \multicolumn{7}{|l|}{ 2-way interactions } \\
\hline$a \times b$ & & & 25.0 & 4 & 656.2 & 2.0 \\
\hline$a \times c$ & & & 18.2 & 2 & 159.1 & 0.5 \\
\hline$b \times c$ & & & 59.3 & 2 & 1429.7 & $4.4^{*}$ \\
\hline \multicolumn{7}{|l|}{ 3-way interactions } \\
\hline$a \times b \times c$ & & & 12.2 & 4 & 578.1 & 1.762 \\
\hline Explained & & $447^{\circ}$ & 98.7 & 17 & 26341.1 & $80.3^{* *}$ \\
\hline Residual & & $289 ?$ & 80.5 & 882 & 328.1 & \\
\hline Total & & 7371 & 79.1 & 899 & 820.0 & \\
\hline
\end{tabular}

${ }^{*} P<0.025,{ }^{* *} P<0.001$.

$29^{\circ} \mathrm{C}\left(F_{2,147}=4.52, P<0.05\right.$, SNK-test $)$. Third, there was a significant interaction between the sex and adult temperature: male flies tended to live longer than females at $20^{\circ} \mathrm{C}$, while the opposite was true at $29^{\circ} \mathrm{C}$ (Table 3).

It appears from Fig. 1a and $\mathrm{b}$ and Table 4 that the differences in longevity between developmental temperature groups are consistent at $L T_{10}, L t_{50}$ and $L T_{90}$. In other words, survival curves at each adult temperature generally ran parallel after $L T_{10}$. One clear exception could be found for males at adult temperature $25^{\circ} \mathrm{C}$, developed at $25^{\circ} \mathrm{C}$ (Fig. 1b). It should also be noted that with increasing adult temperature both $L T_{10}$ values and the survival curve slopes de- creased (respectively: females $r=-0.95, P<0.001$; males $r=-0.90, \quad P<0.001$; females $r=-0.94$, $P<0.001$; males $r=-0.79, P<0.001)$. Thus, it appeared that both the pre-senescent as well as the senescent period were temperature dependent in Drosophila melanogaster. Similar effects have been found for the housefly, Musca domestica (Sohal, 1986, p. 27).

Correlations between longevity and winglength are shown in Table 5. A significant correlation between longevity and winglength was found in only three out of 24 cases. Two of these correlations were negative and one positive. As mentioned earlier, not all samples were of equal size; however, this did not seriously in- 
fluence the results, because we observed no differences in winglength between adult temperature groups (Table 5; females $F_{2,238}=2.993$, ns; males $F_{2,358}=0.376$, ns). Thus, our results do not support the general idea that longevity is positively correlated with body size in Drosophila.
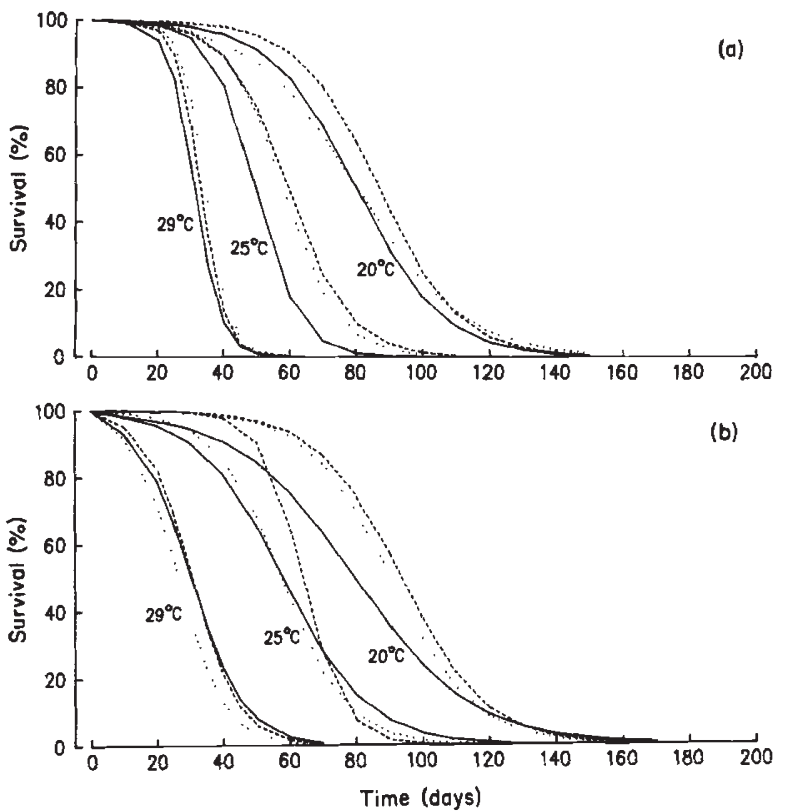

Fig. 1 Logistic survival curves for all (a) female and (b) male temperature groups [developmental temperature $20^{\circ} \mathrm{C}$ $\left.(-) ; 25^{\circ} \mathrm{C}(---) ; 29^{\circ} \mathrm{C}(\cdots \cdot)\right]$.

\section{Discussion}

In this study, adult longevity is influenced by adult temperature as expected from previously published data (e.g. Alpatov \& Pearl, 1929; Hollingsworth, 1968; Lamb, 1968). In general, the life-shortening effect of higher adult temperature in poikilotherms has been explained in terms of the rate of living theory (Pearl, 1928). A modern version of this theory states that 'rate of ageing' is directly related to the rate of unrepaired molecular damage inflicted by the byproducts of oxygen metabolism and is inversely correlated to the efficiency of antioxidant and reparative mechanisms' (Sohal, 1986). In insects, elevated adult temperatures will result in an increase in metabolic rate, probably due to stimulation of physical activity (Sohal, 1986) and thus, in a proportional increase in oxygen-free radicals. However, one would expect a concomitant increase in 'antioxidant defence' activity. Apparently, there is no linear relationship between these two processes in Drosophila, otherwise the pre-senescent period would have been temperature independent. It is thus interesting to note that houseflies exhibiting relatively high levels of physical activity do not show an increase in enzymatic antioxidant defenses, like superoxide dismutase and catalase activity, and it has been suggested that this imbalance between production and elimination of oxygen-free radicals is causally related to the lifespan shortening of these active flies (Sohal $e t$ al., 1984). It is also possible that the non-enzymatic

Table 4 Descriptives of the logistic survival curves, $L T_{10}, L T_{50}$ and $L T_{90}$ (days)

\begin{tabular}{|c|c|c|c|c|c|c|}
\hline & \multicolumn{6}{|c|}{ Adult temperature $\left({ }^{\circ} \mathrm{C}\right)$} \\
\hline & \multicolumn{2}{|l|}{20} & \multicolumn{2}{|l|}{25} & \multicolumn{2}{|l|}{29} \\
\hline & Female & Male & Female & Male & Female & Male \\
\hline \multirow{2}{*}{\multicolumn{7}{|c|}{$\begin{array}{l}\text { Developmental } \\
\text { temperature }\left({ }^{\circ} \mathrm{C}\right) \\
20\end{array}$}} \\
\hline & & & & & & \\
\hline$L T_{10}$ & 51.7 & 41.3 & 34.6 & $\begin{array}{l}30.2 \\
581\end{array}$ & 22.2 & $\begin{array}{l}12.9 \\
30.5\end{array}$ \\
\hline$L T_{50}$ & 80.1 & 79.7 & 49.6 & 58.1 & 31.2 & 30.5 \\
\hline$L T_{90}$ & 108.4 & 118.1 & 64.6 & 85.9 & 40.1 & 48.0 \\
\hline \multicolumn{7}{|l|}{25} \\
\hline$L T_{10}$ & 60.3 & 65.9 & 39.1 & 50.2 & 24.7 & 15.4 \\
\hline$L T_{50}$ & 86.8 & 93.6 & 59.6 & 64.1 & 33.0 & 30.8 \\
\hline$L T_{90}$ & 113.2 & 121.3 & 80.0 & 77.9 & 41.2 & 46.1 \\
\hline \multicolumn{7}{|l|}{29} \\
\hline$L T_{10}$ & 45.7 & 63.4 & 39.5 & 36.0 & 26.1 & 11.3 \\
\hline$L T_{50}$ & 80.3 & 90.5 & 57.9 & 57.5 & 34.4 & 26.6 \\
\hline$L T_{90}$ & 114.9 & 117.7 & 76.3 & 79.0 & 42.7 & 41.9 \\
\hline
\end{tabular}


Table 5 Correlation coefficients $(r)$ for the relation between longevity and winglength for each temperature group. The winglength (s.d. in parentheses) is also given

\begin{tabular}{|c|c|c|c|c|c|c|}
\hline & \multicolumn{6}{|c|}{ Adult temperature $\left({ }^{\circ} \mathrm{C}\right)$} \\
\hline & \multicolumn{2}{|l|}{20} & \multicolumn{2}{|l|}{25} & \multicolumn{2}{|l|}{29} \\
\hline & Female & Male & Female & Male & Female & Male \\
\hline \multicolumn{7}{|l|}{$\begin{array}{l}\text { Developmental } \\
\text { temperature }\left({ }^{\circ} \mathrm{C}\right) \\
20\end{array}$} \\
\hline$r$ & 0.28 & $-0.37^{*}$ & 0.32 & -0.17 & 0.05 & 0.01 \\
\hline winglength & $\begin{array}{l}71.4 \\
(1.5)\end{array}$ & $\begin{array}{l}62.9 \\
(1.4)\end{array}$ & $\begin{array}{l}70.4 \\
(1.9)\end{array}$ & $\begin{array}{l}62.9 \\
(1.2)\end{array}$ & $\begin{array}{l}70.6 \\
(1.8)\end{array}$ & $\begin{array}{l}63.1 \\
(1.7)\end{array}$ \\
\hline$n$ & 16 & 33 & 29 & 37 & 42 & 45 \\
\hline \multicolumn{7}{|l|}{25} \\
\hline $\begin{array}{l}r \\
\text { winglength }\end{array}$ & $\begin{array}{c}-0.34 \\
63.9 \\
(1.5)\end{array}$ & $\begin{array}{c}-0.04 \\
57.5 \\
(1.5)\end{array}$ & $\begin{array}{c}-0.02 \\
64.4 \\
(2.0)\end{array}$ & $\begin{array}{c}0.21 \\
57.3 \\
(1.9)\end{array}$ & $\begin{array}{c}-0.18 \\
65.4 \\
(1.8)\end{array}$ & $\begin{array}{c}0.05 \\
57.2 \\
(1.4)\end{array}$ \\
\hline$n$ & 10 & 40 & 25 & 40 & 42 & 50 \\
\hline \multicolumn{7}{|l|}{29} \\
\hline$r$ & 0.04 & -0.08 & 0.32 & -0.04 & $0.40^{* *}$ & -0.12 \\
\hline winglength & $\begin{array}{l}61.5 \\
(1.5)\end{array}$ & $\begin{array}{l}53.6 \\
(1.6)\end{array}$ & $\begin{array}{l}60.4 \\
(2.0)\end{array}$ & $\begin{array}{l}53.3 \\
(1.5)\end{array}$ & $\begin{array}{l}61.0 \\
(1.7)\end{array}$ & $\begin{array}{l}53.5 \\
(1.6)\end{array}$ \\
\hline$n$ & 11 & 37 & 23 & 39 & 49 & 46 \\
\hline \multicolumn{7}{|l|}{ Total } \\
\hline$r$ & 0.04 & $-0.24^{*}$ & -0.06 & -0.01 & -0.15 & 0.11 \\
\hline$n$ & 37 & 110 & 77 & 116 & 133 & 141 \\
\hline
\end{tabular}

${ }^{*} P<0.05,{ }^{* *} P<0.01$.

antioxidant defences are temperature independent. which would mean that a fixed amount of endogenous antioxidants, such as $\beta$-carotene and ascorbic acid, is present in the cells at each ambient temperature. Therefore, non-enzymatic antioxidant substances are exhausted at a faster rate at elevated temperatures. These lines of reasoning may explain our observation that the pre-senescent period is temperature dependent.

Although our results demonstrate the influence of developmental temperature on adult longevity, they do not support the general opinion that developmental temperature is negatively correlated with lifespan (Mayer \& Baker, 1985). This discrepancy might at least partly be explained by the fact that our study differs in several ways from previous reports on the effect of temperature during development on lifespan.

1 We used three adult temperatures instead of one (Lints \& Lints, 1971a; Cohet, 1975; Economos \& Lints, 1986), which allows analysis of interactive effects (David, 1988);
2 As larval density significantly affects longevity (Zwaan et al., 1991), we controlled the density, in contrast to some other studies (Alpatov \& Pearl, 1929; Burcombe \& Hollingsworth, 1970);

3 Because both group housing (Boulétreau-Merle, 1988) and sexual activity (Partridge, 1986; Partridge et al., 1987; Fowler \& Partridge, 1989; Partridge \& Fowler, 1990) influence lifespan, we housed flies singly and as virgins in contrast to others (Alpatov \& Pearl, 1929; Burcombe \& Hollingsworth, 1970; Lints \& Lints, 1971a; Cohet, 1975; Economos \& Lints, 1986).

Although there may be more confounding variables, at least some of the above mentioned effects might influence the outcome of experiments on effects of developmental temperature on longevity by causing differences between the developmental groups (Cohet, 1975; Economos \& Lints, 1986). Indeed, Cohet \& David (1976) showed that the deleterious effect of mating on female longevity depended on male growth temperature. In addition, mating stimulates egg production in females, which might affect longevity differ- 
ently in each temperature group, because egg production strongly depends on body size (e.g. Lints \& Lints, 1971b). Although virgins lay fewer eggs than mated females, the latter argument is applicable for virgins.

Taking the above into consideration, we conclude that adult longevity is not inversely related to developmental temperature, and thus, that developmental time is not causally related to ageing in Drosophila melanogaster. In our previous study on the effects of larval density and food effects on longevity we reached essentially the same conclusion (Zwaan et al., 1991). However, one could argue that the 'environmental' studies of the type reported here need not be able to demonstrate a possible genetic link between ageing and development. Therefore, selection experiments on developmental time are in progress to describe correlated responses, if any, in longevity and/or body size.

Because adult longevity was generally higher for medium sized flies $\left(25^{\circ} \mathrm{C}\right.$ flies $)$ than for smaller $\left(29^{\circ} \mathrm{C}\right.$ flies) or larger flies $\left(20^{\circ} \mathrm{C}\right.$ flies), no positive correlation was found between lifespan and body size between temperature groups. It appeared, however, that also within groups longevity was independent of adult body size, although size variation within these groups was relatively small. In most of the studies that reported such a relationship, larval density was uncontrolled. For instance, Partridge \& Farquhar (1983) obtained variation in thorax size through sampling adults from culture bottles which had been in population cages for 4 weeks. It appeared that during the emergence of flies from these bottles, the size of the adults decreased. However, eggs laid during the fourth week had developed in food which had previously been burrowed by larvae hatched from eggs laid during the preceding weeks. Therefore, flies emerging from the former group of eggs might well be smaller and live shorter, because of the less favourable conditions in the culture bottles. As an explanation for their observed positive correlation between longevity and body size, Partridge \& Farquhar (1983) have suggested that larger flies have a lower energy expenditure per unit weight than smaller ones, and that this may imply that smaller flies are forced to put less energy into bodily repair when other activities, e.g. reproduction, demand energy. Hunter (1964), however, has shown that, for the corresponding temperature range, respiration rates per unit weight were independent of growth temperature and, thus, independent of body size. Moreover, if adult body size is varied through larval crowding, smaller flies live longer (Zwaan et al., 1991). The conclusion therefore seems legitimate, that adult longevity does not depend on the size of the imago (see also, Lints \& Lints, 1971b).
It has been shown that developmental temperature significantly influences genetic and phenotypic correlations between life-history traits (Giesel et al., 1982; Service \& Rose, 1985). The nature of these processes are not yet understood. It is possible that the superiority in longevity of ' $25^{\circ} \mathrm{C}$ reared' flies stems from the laboratory history of this strain. Since its capture, this strain has been maintained at $25^{\circ} \mathrm{C}$, thus transfer to other developmental temperatures may have disrupted the adaptive genetic architecture, resulting in reduced longevity. A similar explanation has been proposed for the differences in phenotypic fitness associations between field and laboratory derived flies (Kohane \& Parsons, 1986; domestication).

In summary, the main inference of this and our previous (Zwaan et al., 1991) report is that pre-imaginal developmental time and adult body size are no causal determinants of adult longevity.

\section{Acknowledgements}

These investigations were supported by the Foundation for Biological Research (BION), which is subsidized by the Netherlands Organization for Scientific Research (NWO; grant no. 811-436-106). We are grateful to Professor W. van Delden for comments on earlier drafts of this manuscript, and to Henk Mulder for preparing the figures.

\section{References}

ALPATOV, w. W. AND PEARL, R. 1929. Experimental studies on the duration of life. XII. Influence of temperature during the larval period and adult life on the duration of the life of the imago of Drosophila melanogaster. Am. Nat., 63, 37-67.

ARKING, R. 1987. Successful selection for increased longevity in Drosophila: analysis of the survival data and presentation of a hypothesis on the genetic regulation of longevity. Exp. Geront., 22, 199-220.

BARKER, J. S. F. AND PODGER, R. N. 1970. Interspecific competition between Drosophila melanogaster and Drosophila simulans: effects of larval density on viability, developmental period and adult body weight. Ecology, 51, 170-189.

Boulétreau-Merle, J. 1988. Biological factors. In: Lints, F. A. and Soliman, M. H. (eds) Drosophila as a Model Organism for Ageing Studies, Blackie, London, pp. 85-96.

BURCOMBE, J. V. AND hOLLINGSWORTH, M. J. 1970. The relationship between developmental temperature and longevity in Drosophila. Gerontologia, 16, 172-181.

COHET, y. 1975. Epigenetic influences on the lifespan of the Drosophila: existence of an optimal growth temperature for adult longevity. Exp. Geront., 10, 181-184.

COHET, Y. AND DAVID, J. R. 1976. Deleterious effects of copulation in Drosophila females as a function of growth temp- 
erature of both sexes. Experientia, 32, 696-697.

COMForT, A. 1968. Feasibility in age research. Nature, 217, 320-322.

DAVID, J. R. 1988. Temperature. In: Lints, F. A. and Soliman, M. H. (eds) Drosophila as a Model Organism for Ageing Studies, Blackie, London, pp. 33-45.

ECONOMOS, A. C. AND LINTS, F. A. 1986. Developmental temperature and lifespan in Drosophila melanogaster. I. Constant developmental temperature: evidence for physiological adaptation in a wide temperature range. Gerontology, 32, 18-27.

FOWLER, K. AND PARTRIDGE, L. 1989. A cost of mating in female fruitflies. Nature, 338, 760-761.

GIESEL, J. T., MURPhy, P. A. AND MANLOVE, M. N. 1982. The influence of temperature on genetic interrelationships of life history traits in a population of Drosophila melanogaster: what tangled data sets we weave. Am. Nat., 119, 464-479.

HOLLiNGSWORTH, M. J. 1968. Environmental temperature and life span in poikilotherms. Nature, 218, 869-870.

HUNTER, A. S. 1964. Effects of temperature on Drosophila. I. Respiration of Drosophila melanogaster grown at different temperatures. Comp. Biochem. Physiol., 11, 411-417.

KIDWELL, J. F. AND MALICK, L. 1965. The effect of genotype, mating status, weight and egg production on longevity in Drosophila melanogaster. J. Hered., 58, 169-172.

KOHANE, M. J. AND PARSONS, P. A. 1986. Environment-dependent fitness differences in Drosophila melanogaster: temperature, domestication and the alcohol dehydrogenase locus. Heredity, 57, 289-304.

LAMB, M. J. 1968. Temperature and lifespan in Drosophila. Nature, 220, 808-809.

LiNTS, F. A. 1978. Genetics and Ageing. Interdisciplinary Topics in Gerontology, Karger, Basel.

LINTS, F. A. 1988. Genetics. In: Lints, F. A. and Soliman, M. H. (eds) Drosophila as a Model Organism for Ageing Studies, Blackie, London, pp. 99-118.

LINTS, F. A. AND LINTS, C. v. 1971a. Influence of preimaginal environment on fecundity and ageing in Drosophila melanaogaster hybrids. II. Preimaginal temperature. Exp. Geront., 6, 417-426.

LINTS, F. A. AND LINTS, C. v. 1971 b. Influence of preimaginal environment on fecundity and ageing in Drosophila melanogaster hybrids. III. Developmental speed and lifespan. Exp. Geront., 6, 427-445.

MAYER, P. J. AND BAKER, G. T. 1985. Genetic aspects of Drosophila as a model system of eukaryotic aging. Int.
Rev. Cytol., 95, 61-102.

PARTRIDGE, L. 1986. Sexual activity and life-span. In: Collatz, K. G. and Sohal, R. S. (eds) Insect Aging, Springer-Verlag, Berlin, pp. 45-54.

PARTRIDGE, L. AND FARQUHAR, M. 1981. Sexual activity reduces lifespan of male fruitflies. Nature, 294, 580-582.

PARTRIDGE, L. AND FARQUHAR, M. 1983. Lifetime mating success of male fruitflies (Drosophila melanogaster) is related to their size. Anim. Behav., 31, 871-877.

PARTRIDGE, L. AND FOWLER, K. 1990. Non-mating costs of exposure to males in female Drosophila melanogaster. J. Insect Physiol., 36, 419-425.

PARTRIDGE, L., FOWLER, K., TREVITT, s. AND SHARP, w. 1986. An examination of the effects of males on the survival and egg-production rates of female Drosophila melanogaster. J. Insect Physiol., 32, 925-929.

PARTRIDGE, L., GREEN, A. AND FOWLER, K. 1987. Effects of eggproduction and of exposure to males on female survival in Drosophila melanogaster. J. Insect Physiol., 33, 745-749.

PEARL, R. 1928. The Rate of Living. Knopf, New York.

POWSNER, L. 1935. The effects of temperature on the duration of the developmental stages of Drosophila melanogaster. Physiol. Zool., 8, 475-520.

PROUT, T. 1958. A rapid method for measuring winglength. Dros. Inf. Serv., 32, 170-171.

RICKLEFS, R. E. 1967. A graphical method of fitting equations to growth curves. Ecology, 48, 978-983.

SER VICE, P. M. AND ROSE, M. R. 1985. Genetic covariation among life-history components: the effect of novel environments. Evolution, 39, 943-945.

SOHAL, R. S. 1986. The rate of living theory: a contemporary interpretation. In: Collatz, K. G. and Sohal, R. S. (eds) Insect Aging, Springer-Verlag, Berlin, pp. 23-44.

SOHAL, R. S., ALLEN, R. G., FARMER, K. J. AND PROCTER, J. 1984. Effect of physical activity on superoxide dismutase, catalase, inorganic peroxides and glutathione in the adult male housefly, Musca domestica. Mech. Ageing Dev., 26, 75-81.

SOKAL, R. R. AND ROHLF, F. J. 1969. Biometry. W.H. Freeman and Company, San Francisco.

TANTAWY, A. O. AND VETUKHIV, M. o. 1960. Effects of size on fecundity, longevity and viability in populations of Drosophila pseudoobscura. Am. Nat., 94, 395-403.

ZWAAN, B. J., BIJLSMA, R. AND HOEKSTRA, R. F. 1991. On the developmental theory of ageing. I. Starvation resistance and longevity in Drosophila melanogaster in relation to preadult breeding conditions. Heredity, 66, 29-39. 